Anuario de

Derechos Humanos 2005 


\title{
Fallo Páez con Baraona: Libertad de Expresión e Interés Público
}

\author{
María José Eva Parada*
}

\section{Antecedentes}

E I derecho a la libertad de expresión, y su tradicional colisión con el derecho a la honra, una vez más pone a prueba el trabajo de los tribunales chilenos con un caso que involucra a una autoridad pública: un Senador de la República.

El 22 de junio de 2004 el Juzgado de Garantía de Puerto Montt condenó como autor del delito de injurias graves cometido a través de medios de comunicación social al abogado Carlos Baraona Bray, en contra del Senador de la República Sergio Páez Verdugo ${ }^{1}$, absolviéndolo del delito de calumnias. La Corte Suprema, rechazando el recurso de nulidad interpuesto por el querellado, confirmó esta sentencia ${ }^{2}$.

En el momento en que ocurren los hechos que dan lugar a esta querella por injurias y calumnias, el Juzgado de los Muermos (Décima Región) estaba realizando una investigación sobre los delitos de tráfico de influencias, cohecho y asociación ilícita que vinculaba a una serie de funcionarios públicos y que había significado la orden de detención de Carlos Weber, Director Ejecutivo de la Corporación Nacional Forestal de Chile (en adelante "CONAF"). Esta detención dio lugar a una serie de comentarios y artículos noticiosos donde se hablaba de tráfico de influencias, tala ilegal de alerce, asociación ilícita, redes de protección, cohecho y presiones políticas sobre la CONAF. Esta situación originó, incluso, el intento de crear una comisión investigadora por parte de la Cámara de Diputados, ya que habría estado vinculado al caso un senador de la región.

En este contexto, Carlos Baraona, quien tenía conocimiento del juicio seguido en Los Muermos, da una serie de entrevistas en las que indicó que el Senador Páez sería el político que figuraba en ese expediente y que habría ejercido presiones sobre autoridades de la Décima Región a fin de permitir la ocupación ilegal de propiedades y la tala ilícita de alerce, señalando que algunas autoridades de la Región eran fieles sirvientes del Senador Páez en el proceso del saneamiento irregular de títulos de dominio y la obtención ilegal de planes de manejo de alerces, todo lo cual obedecía a promesas electorales ${ }^{3}$.

El propósito de este comentario es analizar este fallo a la luz de las resoluciones internacionales que podemos encontrar en esta materia, en particular, lo referente al estándar que se ha establecido para las

* Abogada, Investigadora, Centro de Derechos Humanos, Facultad de Derecho, Universidad de Chile.

1 Sentencia de 22 de junio de 2004, Rol Único No0410008047-3, del Juzgado de Garantía de Puerto Montt dictada por el magistrado Patricio Rondini FernándezDávila. La pena asignada al delito fue de 300 días de reclusión menor en su grado mínimo y multa de 20 unidades tributarias mensuales, más la accesoria de suspensión de cargos $u$ oficios públicos por el periodo de la condena. Se otorgó remisión condicional de la pena, debiendo el condenado sujetarse a control administrativo y asistencia a la sección correspondiente de Gendarmería de Chile por el término de un año.

2 Sentencia de 9 de septiembre de 2004, Segunda Sala de la Corte Suprema. Este caso fue presentado a la Comisión Interamericana de Derechos Humanos en marzo de 2005; a la fecha aún no se resuelve su admisibilidad.

3 Sobre establecimiento de los hechos, ver el Considerando Quinto, sentencia de 22 de junio de 2004.

Este comentario, junto con el documento principal a que se refiere, están disponibles en formato digital en www.anuariocdh.uchile.cl 
4 Considerando Noveno letra b.- de la sentencia en comento.

5 Artículo 412 y siguientes del Código Penal.

Conforme al artículo 412 es calumnia "la imputación de un delito determinado pero falso y que pueda actualmente perseguirse de oficio".

6 Artículo 416 y siguientes del Código Penal.

Conforme al artículo 416

"es injuria toda acción proferida o acción ejecutada en deshonra, descrédito o menosprecio de otra persona".

7 Considerando Noveno, letra c.-, sentencia en comento, énfasis agregado.

8 Considerando Noveno letra d.- de la sentencia en comento.

9 Ver Considerando Décimo del fallo en comento.

${ }^{10}$ Este delito está previsto en el artículo $417 \mathrm{~N}^{\circ} 3$ del Código Penal y está sancionado por el artículo 418 del mismo cuerpo legal. limitaciones a la libertad de expresión cuando se trata de opiniones o comentarios con respecto a autoridades públicas.

\section{Consideraciones del Tribunal}

El fallo estableció que "si bien [el querellado] habló de presiones ejercidas por el querellante no las circunscribió en un ilícito penal específico ${ }^{\prime \prime}$, razón por la cual el delito de calumnias ${ }^{5}$ no se había configurado correspondiendo, por tanto, absolverlo de esta imputación.

Con respecto al delito de injurias ${ }^{6}$, el tribunal comenzó el análisis haciendo referencia a un fallo de la Corte Suprema de Chile que señala:

"lo que suele designarse como animus injuriandi no es sino el dolo del delito" de injuria, mismo que "consiste simplemente en saber que la expresión que se proferirá o la acción que se ejecutará es deshonrosa, desacreditadora o menospreciadora de aquel a quien se refiere, y en querer proferirla o ejecutarla". "Cuando se habla de que otros ánimos, como el de corregir o informar, sí suprimen el contenido de injusto de este delito, lo que realmente quiere decirse es que el sentido de las expresiones proferidas o las acciones ejecutadas, en el contexto de que objetivamente forman parte, carecen de capacidad, para deshonrar, desacreditar o menospreciar al ofendido o bien que, teniéndola, están puestas al servicio de un interés superior a la defensa del honor de la víctima, en cuyo caso nos encontramos más bien frente a una situación de justificación del comportamiento ofensivo y no de atipicidad del mismo"'.

En base a lo anterior, estableció que había habido dolo en las expresiones de Baraona dado que "ha manifestado que realizó una crítica política y, por ende, a su parecer prima la libertad de expresión por sobre el honor de una persona, de lo cual se colige meridianamente claro que conocía el carácter deshonroso de sus expresiones, sin perjuicio de justificarlas en el legítimo derecho a informar ${ }^{\prime \prime}$.

Al respecto, al analizar la causal de justificación del artículo 10 № 10 del Código Penal-obrar en ejercicio legítimo de un derecho-alegada por la defensa, en virtud de la cual señalaba que Baraona habría estado realizando una crítica política y que, por lo tanto, el presente problema era un asunto de colisión de derechos entre el derecho al honor y el derecho a informar, el tribunal, pese a tomar en cuenta lo señalado por la Corte Suprema acerca de la posibilidad de supresión del contenido injusto del delito de injurias o de situación de justificación del comportamiento ofensivo, estimó que en este caso "los dichos del querellado no pueden considerarse como revestidos de la seriedad y razonabilidad requerida para que su derecho a informar deba prevalecer por sobre el honor del querellante, por cuando no existe proporcionalidad entre el sacrificio del honor y los beneficios que se pudieran obtener de la crítica" ${ }^{\prime 9}$. De esta manera, estableció que el querellado debía ser condenado por el delito de injuria grave cometida a través de medios de comunicación social ${ }^{10}$. 
Para concluir lo anterior, el tribunal atendió a que el querellado no había podido probar sus dichos ya que, entre otras, las presiones que él había denunciado fueron desdichas por los supuestos presionados ${ }^{11}$ resultando aventuradas sus expresiones; las supuestas promesas electorales no pudieron ser corroboradas, siendo vistas por el tribunal como una mera conjetura $^{12}$ por parte del querellado; y los antecedentes que decía tener nunca fueron acompañados a la causa. Asimismo, el tribunal consideró que el querellado en sus declaraciones no planteó una hipótesis, sino que realizó afirmaciones, debiéndose atribuirle un mayor grado de responsabilidad ${ }^{13}$. En definitiva concluyó que el querellado imputó al querellante "una falta de moralidad consistente en presiones a autoridades públicas para el saneamiento de títulos de dominio y tala ilegal debido a promesas electorales, sin que contara con antecedentes que dieran cuenta de ellos ..."14 ${ }^{\prime 1}$, presentándose para el juzgador desproporcionado sacrificar el derecho al honor por sobre la libertad de expresión cuando no hay respaldo para ello. Por lo tanto, además de considerar los dichos injuriosos por sí mismos, estableció que no habían podido probarse.

Un elemento ausente entre las consideraciones del tribunal, es el interés público, cuestión que no es ponderada en el fallo, desconociendo que este caso involucraba una cuestión de tal entidad. A nuestro modo de ver, ésta es precisamente una de las mayores debilidades de la sentencia en análisis.

\section{Libertad de Expresión y Honor: Estándares Internacionales}

El derecho a la libertad de expresión e información, en el cual se ampara el querellado para defender sus dichos, ha sido consagrado tanto a nivel nacional como internacional. Nuestro ordenamiento jurídico en el artículo 19 №12 de la Constitución Política de la República (en adelante "Constitución"), asegura a todas las personas:

"La libertad de emitir opinión y la de informar, sin censura previa, en cualquier forma y por cualquier medio, sin perjuicio de responder de los delitos y abusos que se cometan en el ejercicio de estas libertades, en conformidad a la ley, la que deberá ser de quórum calificado".

Por su parte, el artículo 13 de la Convención Americana sobre Derechos Humanos ${ }^{15}$ (en adelante "CADH"), que rige en Chile en virtud de lo dispuesto en el artículo $5^{\circ}$, inciso segundo de la Constitución, establece en lo que a este caso interesa:

1. Toda persona tiene derecho a la libertad de pensamiento y de expresión. Este derecho comprende la libertad de buscar, recibir y difundir informaciones e ideas de toda índole, sin consideración de fronteras, ya sea oralmente, por escrito o en forma impresa o artística, o por cualquier otro procedimiento de su elección.

2. El ejercicio del derecho previsto en el inciso precedente no puede estar sujeto a previa censura sino a responsabilidades ulteriores, las que deben estar expresamente fijadas por la ley y ser necesarias para asegurar:
11 Considerando Décimo letras a. y b.

12 Considerando Décimo, letra c.

13 Considerando Décimo, letra $f$.

${ }^{14}$ Considerando Décimo, letra $h$.

15 La Convención Americana sobre Derechos Humanos fue adoptada en San José de Costa Rica en 1969, vigente en Chile. En similares términos este derecho se encuentra consagrado en el artículo 19 del Pacto Internacional de Derechos Civiles y Políticos de 1966, vigente en Chile. 
16 Caso Ricardo Canese, párr.77; Caso Herrera Ulloa, párr. 109; Caso Última Tentación de Cristo, párr. 65.

17 Ver Caso Ricardo Canese párr. 79; Caso Herrera Ulloa, párr. 111; Caso La Última Tentación de Cristo, párr. 66; Caso Ivcher Bronstein, párr. 148.

${ }^{18} \mathrm{Al}$ respecto ver de la Corte Europea de Derechos Humanos, por ejemplo, Handyside $v$. United Kingdom, sentencia de 7 de diciembre de 1976, párr. 49; Caso Lingens v. Austria, sentencia de 8 de julio de 1986, párr.41. En la Corte I.D.H. La Colegiación Obligatoria de Periodistas, Opinión Consultiva OC-5/85 del 13 de noviembre de 1985, serie A N5, párr. 70; Caso La Última Tentación de Cristo, sentencia de 5 de febrero de 2001, serie $\mathrm{C} \mathrm{N}^{\circ} 73$, párr. 69; Caso Herrera Ulloa, sentencia de 2 de julio de 2004, serie C №106, párr. 113; Caso Ivcher Bronstein, sentencia de 6 de febrero de 2001, serie $\mathrm{C} \mathrm{N}^{\circ} 74$, párr. 152

${ }^{19}$ Corte I.D.H., Caso Ricardo Canese, sentencia de 31 de agosto de 2004, serie C No111, párr. 86; Caso Herrera Ulloa, párr. 116. a) el respeto a los derechos o a la reputación de los demás, $o$

b) la protección de la seguridad nacional, el orden público o la salud o la moral públicas.

El derecho a la honra, por su parte, encuentra amparo en el artículo $19 \mathrm{~N}^{0} 4$ de la Constitución que consagra "el respeto y la protección de la vida privada y pública y a la honra de la persona y de su familia".

Asimismo, la CADH consagra este derecho en el artículo 11 señalando:

1. Toda persona tiene derecho al respeto de su honra y al reconocimiento de su dignidad.

2. Nadie puede ser objeto de injerencias arbitrarias o abusivas en su vida privada, en la de su familia, en su domicilio o en su correspondencia, ni de ataques ilegales a su honra o reputación.

3. Toda persona tiene derecho a la protección de la ley contra esas injerencias o esos ataques.

La Corte Interamericana de Derechos Humanos (en adelante "la Corte" o "Corte I.D.H."), explicando el contenido del derecho a la libertad de expresión, ha señalado que comprende tanto el derecho a expresar las propias ideas y pensamientos, como el derecho y libertad de buscar, recibir y difundir informaciones e ideas de toda índole. De esta manera, al restringirse ilegalmente la libertad de expresión no sólo se viola el derecho de un individuo en particular, sino el de la sociedad toda de recibir ideas e informaciones. En este sentido, se ha reconocido una dimensión individual y una social de este derecho, donde la dimensión individual está dada por el derecho de cada uno a expresarse por cualquier medio y hacerlo llegar al mayor número de destinatarios posibles $^{16}$; mientras que la social implica el derecho de tratar de comunicar a los otros las propias ideas y opiniones, conllevando también el derecho de todos a conocer opiniones, relatos y noticias. Al respecto, la Corte ha dicho que tiene tanta importancia el conocimiento de la opinión ajena como el derecho a difundir la propia ${ }^{17}$.

Este mismo órgano, siguiendo los estándares de otras instancias internacionales, ha recalcado la importancia de la libertad de expresión para la democracia, señalando que debe ser considerada como la piedra angular de una sociedad democrática ${ }^{18}$. Asimismo, ha declarado que "[s]in una efectiva libertad de expresión, materializada en todos sus términos, la democracia se desvanece, el pluralismo y la tolerancia empiezan a quebrantarse, los mecanismos de control y denuncia ciudadana se comienzan a tornar inoperantes $y$, en definitiva, se crea el campo fértil para que sistemas autoritarios se arraiguen en la sociedad" ${ }^{\prime 19}$.

Ahora bien, tanto la Corte como otros organismos internacionales han reconocido que la libertad de expresión no es un derecho absoluto, siendo el respeto a los derechos o la reputación de los demás una restricción legítima. 
En este contexto es donde debe ser analizado el caso que nos ocupa ya que, como hemos señalado, se habría generado una colisión entre la libertad de expresión y la honra de un senador. En este sentido la Corte I.D.H. señala como tema relevante el "distinguir entre las restricciones que son aplicables cuando el objeto de la expresión se refiera a un particular y, por otro lado, cuando haga referencia a una persona pública como, por ejemplo, un político"20

Al respecto, la Corte señala que "tratándose de funcionarios públicos, de personas que ejercen funciones de una naturaleza pública y de políticos, se debe aplicar un umbral diferente de protección, el cual no se asienta en la calidad del sujeto, sino en el carácter de interés público que conllevan las actividades o actuaciones de una persona determinada. Aquellas personas que influyen en cuestiones de interés público se han expuesto voluntariamente a un escrutinio público más exigente $y$, consecuentemente, en ese ámbito se ven sometidos a un mayor riesgo de sufrir críticas, ya que sus actividades salen del dominio de la esfera privada para insertarse en la esfera del debate público. En este sentido, en el marco del debate público, el margen de aceptación y tolerancia a las críticas por parte del propio Estado, de los funcionarios públicos, de los políticos e inclusive de los particulares que desarrollan actividades sometidas al escrutinio público, debe ser mucho mayor que el de los particulares" ${ }^{\prime 21}$. Esto cobra especial relevancia al entender, como señala la Corte, que el control democrático por parte de la sociedad a través de la opinión pública, fomenta la transparencia de las actividades estatales, "razón por la cual debe existir un margen reducido a cualquier restricción del debate político o del debate sobre cuestiones de interés público"'22. En este sentido, este mismo criterio debe utilizarse "respecto de asuntos de interés público en los cuales la sociedad tiene un legítimo interés de mantenerse informada, de conocer lo que incide sobre el funcionamiento del Estado, afecta intereses o derechos generales, o le acarrea consecuencias importantes" ${ }^{\prime 23}$.

Entonces, si bien la libertad de expresión admite restricciones -entre ellas el respeto y reputación de los demás-, ellas deben ser cuidadosamente aplicadas cuando se trata de expresiones concernientes a funcionarios públicos o personas que ejercen funciones de naturaleza pública, ya que esto resulta esencial para un sistema verdaderamente democrático.

Sin perjuicio de lo anterior, la Corte se hace cargo particularmente del problema de la colisión con el derecho a la honra de las personas (artículo 11 de la CADH), que es de por sí un límite a la expresión o injerencia de particulares o del Estado. En este sentido, la Corte ha señalado, como expusimos previamente, que si bien los funcionarios públicos deben estar expuestos a un mayor escrutinio de sus acciones, ello no significa que su honor no deba ser jurídicamente protegido conforme a los principios del pluralismo, lo que también es aplicable al caso de los particulares que ejercen actividades de carácter público ${ }^{24}$.
${ }^{20}$ Corte I.D.H., Caso Herrera Ulloa, párr. 125. Corte Europea de Derechos Humanos: Case of Dichand and others $v$. Austria, para. 39; Case of Lingens vs. Austria, para. 42.

${ }^{21}$ Corte I.D.H., Caso Ricardo Canese, párr. 103.

22 Corte I.D.H., Caso Ivcher Bronstein, párr. 155; Caso Herrera Ulloa, párr. 127. En el sistema europeo: Feldek v. Slovakia, sentencia de 12 de julio de 2001, párr. 83; y Sürek and Özdemir v. Turkey, sentencia de 8 de julio de 1999, párr. 60.

23 Corte I.D.H., Caso Ricardo Canese, párr. 98.

${ }^{24}$ Corte I.D.H., Caso Ricardo Canese, párr. 100; Caso Herrera Ulloa, párr. 128. 


\section{Conclusiones}

No cabe duda que el caso chileno comentado versa sobre un asunto de interés público, en la medida en que se ve afectado el correcto desarrollo del ecosistema al ocurrir y ser denunciadas una serie de irregularidades en la fiscalización y protección de una especie arbórea. Asimismo, una de las partes de este caso, quien resultara afectado por las expresiones, es una autoridad pública: un Senador de la República. De ahí, entonces, que sea perfectamente lógico concluir que este caso es muy similar a los tratados por la Corte I.D.H. (y por otras instancias internacionales), donde se ha consagrado que el juzgador debe utilizar un criterio más flexible a la hora de analizar los dichos que se refieren a una autoridad.

Nos parece indispensable, acorde con los principios del pluralismo democrático, que al momento de fallar estos casos, los tribunales deben ponderar el respeto a los derechos o a la reputación de los demás con el valor que tiene en una sociedad democrática el debate abierto sobre temas de interés o preocupación pública. En este sentido, parece conveniente dejar planteado para futuros debates acaso nuestros tribunales, de haber tenido a la vista el desarrollo jurisprudencial internacional en materia de libertad de expresión e información y autoridades públicas, no hubieran analizado el caso desde una perspectiva diferente, Ilegando, en consecuencia, a una resolución distinta del mismo. 